\title{
ANALISIS PERENCANAAN PONDASI DINAMIS UNTUK MENDUKUNG MESIN TURBIN PADA PABRIK GULA CUKIR JOMBANG
}

\author{
Dynamic Foundation Design Analysis To Support The Turbine Engine At The Sugar Factory of \\ Cukir Jombang
}

\author{
Ernawan Setyono ${ }^{1} \&$ Abdiyah Amudi ${ }^{2}$
}

${ }^{1 \& 2}$ Jurusan Teknik Sipil Universitas Muhammadiyah Malang

Alamat korespondensi : Jl. Raya Tlogomas 246 Malang 65144

\begin{abstract}
Foundation plan to shore up machine load, the foundation system influinced by shaking load, the load caused by imbalance machine force and static system load (foundation and machine). Reminding the change shaking load, according to time and tempo function which long and working in repetition, it caused the structure would be difference compared with structure which accepted static load only. Foundation type used in this planning was block type foundation where in its calculation to find out the condition fulfilled dimention, using trial and error. In general, the foundation weight was the multiple times of machine weight. Direction amplitudo $z=0,127 \mathrm{~mm}$, amplitudo direction $x=0,142 \mathrm{~mm}$, amplitudo direction $y=0,19 \mathrm{~mm}$, amplitudo vertical combination $=0,0083 \mathrm{rad}$, amplitudo horizontal combination $=0,0027 \mathrm{rad}$ and turque amplitudo $=0,00159$ rad. Dimention which able to resist the machine dynamic load by length $9,2 \mathrm{~m}$, wide 4,8 $\mathrm{m}$, and deep $2,8 m$.
\end{abstract}

Keywords : Dynamic Foundation, Elastic Half Space Method

\begin{abstract}
Abstrak
Perencanaan pondasi apabila harus menopang beban berupa mesin, maka sistem pondasi tersebut dipengaruhi oleh beban yang bergetar, beban ini disebabkan oleh gaya-gaya mesin yang tidak seimbang dan beban statis sistem (pondasi dan mesin). Mengingat bekerjanya beban yang bergetar tersebut berubah berdasarkan fungsi waktu dan tempo yang relatif lama dan bekerja secara berulang-ulang, maka hal ini menyebabkan kelakuan struktur akan berbeda apabila dibandingkan dengan struktur yang menerima beban statis saja. Tipe pondasi yang dipakai dalam perencanaan ini adalah tipe pondasi blok, dimana dalam perhitungannya untuk mendapatkan dimensi yang memenuhi syarat menggunakan cara coba-coba. Secara umum berat pondasi adalah sekian kali dari berat mesin. Amplitudo arah $\mathrm{z}=$ $0,127 \mathrm{~mm}$, amplitudo arah $\mathrm{x}=0,142 \mathrm{~mm}$, amplitudo arah $\mathrm{y}=0,19 \mathrm{~mm}$, amplitudo kombinasi vertikal $=$ $0,0083 \mathrm{rad}$, amplitudo kombinasi horizontal $=0,0027 \mathrm{rad}$ dan amplitudo torsi $=0,00159 \mathrm{rad}$, Dimensi yang mampu menahan beban dinamis mesin yaitu dengan panjang $9,2 \mathrm{~m}$, lebar 4,8 $\mathrm{m}$ dan kedalaman 2,8 $\mathrm{m}$
\end{abstract}

Kata kunci : Pondasi Dinamis, Metode Elastic Half Space

\section{PENDAHULUAN}

Pabrik gula Cukir Jombang ini merupakan salah satu pabrik yang menggunakan mesin-mesin besar. Pada pabrik tersebut telah menggunakan mesin turbin untuk menyuplai kebutuhan listrik pada pabrik tersebut. Dengan adanya mesin besar tersebut tentunya harus dipersiapkan tempat agar dalam pengoprasiannya nanti bisa lancar bagi penguna mesin tersebut dan keamanan bagi mesin itu sendiri. Oleh sebab itu sudah barang tentu harus dibuatkan sebuah pondasi yang kuat dan aman sesuai dengan perilaku dari pembebanannya. Adapun rumusan masalah dalam penelitian ini adalah berapakah amplitudo yang bekerja pada pondasi pendukung mesin turbin pada pabrik gula Cukir Jombang dan berapakah dimensi pondasi sehingga memenuhi syarat-syarat perencanaan. Adapun tujuan dari penelitian ini adalah untuk mengetahui amplitudo yang bekerja pada pondasi pendukung mesin turbin pada pabrik gula Cukir Jombang dan untuk mengetahui dimensi pondasi sehingga memenuhi syarat-syarat perencanaan. 
Batasan masalah dalam penelitian ini adalah perencanaan ini metode analisa dinamis yang dipakai adalah metode lumped parameter system, untuk menentukan lumped parameter system metode yang dipakai adalah metode elastis half space, Pondasi yang dipakai adalah tipe blok, dan dalam perencanaan ini tidak membahas aspek ekonomis suatu struktur karena waktu penelitian sedikit sehingga tidak mencukupi untuk membahas aspek ekonomisnya.

\section{Analisa dan perencanaan pondasi tipe blok}

a. Sifat geometric pondasi mesin

- $\quad$ Pusat gravitasi

Mesin dan pondasi dapat dibagi dalam beberapa bagian massa dan bentuk gravitasi tetap, misalkan koordinat pusat gravitasi masing-masing massa elemen dihubungkan pada sumbu yang berubah-ubah (xi, yi, zi) dari pusat gravitasi mesin dan pondasi didapat : (Bowles, J.E, 1993 : 55)

$$
\bar{x}=\frac{\sum_{i} m i x i}{\sum_{i} m i}
$$

$$
\bar{y}=\frac{\sum_{i} m i y i}{\sum_{i} m i}
$$

$$
\bar{z}=\frac{\sum_{i} m i z i}{\sum_{i} m i}
$$

Momen inersia dasar pondasi

$$
\begin{gathered}
I_{x}=\frac{B^{3} L}{12} \\
I_{y}=\frac{B L^{3}}{12}
\end{gathered}
$$

$$
I_{z}=I_{x}+I_{y}
$$

Pada saat dibebani maka gaya-gaya yang terjadi adalah sebagai berikut : (Prakash, S, 1988 : 213)

- Translasi sepanjang sumbu z (gaya vertikal)

- Translasi sepanjang sumbu x (gaya lateral)
- Translasi sepanjang sumbu y (gaya longitudinal)

- Putaran pada sumbu x (pitching)

- Putaran pada sumbu z (torsi)

- Putaran pada sumbu y (rocking)

\section{Perhitungan Akhir Pondasi}

- Analisa getaran vertical (Sidartha, $1996: 15-28)$ - Perhitungan konstanta kekakuan

$$
k z=G r o\left(C i+\frac{G s \cdot h}{\text { G.ro }} S i\right)
$$

Dimana :

$\mathrm{G}=$ modulus geser $\operatorname{tanah}\left(\mathrm{t} / \mathrm{m}^{2}\right)$

ro $=$ radius ekivalen $(\mathrm{m})$

$\mathrm{h}=$ kedalaman tertanam $(\mathrm{m})$

$\mathrm{Ci}=$ kohesifitas tanah

$\mathrm{Si}=$ gaya geser ultimit,

- Perhitungan frekuensi natural

$$
f_{n z}=\frac{1}{2 \pi} \times \sqrt{\frac{k_{z}}{m}}
$$

Dimana :

$\mathrm{k}_{\mathrm{z}}=$ konstanta kekakuan $(\mathrm{t} / \mathrm{m})$

$\mathrm{m}=$ massa struktur pondasi (t.m/det $\left.{ }^{2}\right)$

- Perhitungan amplitudo vertikal

$$
A_{z d}=\frac{P_{z}}{k_{z} \sqrt{\left(1-\left(\frac{\omega}{\omega_{n z}}\right)^{2}\right)^{2}+\left(2 D_{z}\left(\frac{\omega}{\omega_{n z}}\right)\right)^{2}}}
$$

Dimana :

$\mathrm{P}_{\mathrm{z}}=$ beban dinamis (t.rad $\left.{ }^{2}\right)$

$\mathrm{D}_{\mathrm{z}}=$ redaman

$\mathrm{k}_{\mathrm{z}}=$ konstanta kekakuan $(\mathrm{t} / \mathrm{m})$

ù = kecepatan operasi $(\mathrm{rad} / \mathrm{sec})$

$\grave{\mathrm{u}}_{\mathrm{nz}}=$ kecepatan natural $(\mathrm{rad} / \mathrm{sec})$

- Analisa getaran horizontal

- Perhitungan konstanta kekakuan

$$
k x=G r o\left(C_{x 1}+\frac{G s \cdot h}{G . r o} S_{x 1}\right)
$$

Dimana :

$\mathrm{G}=$ modulus geser $\tan a \mathrm{~h}\left(\mathrm{t} / \mathrm{m}^{2}\right)$

ro $=$ radius ekivalen $(\mathrm{m})$ 
$\mathrm{h}=$ kedalaman tertanam (m)

$\mathrm{C}_{\mathrm{x} 1}=$ kohesifitas tanah

$\mathrm{S}_{\mathrm{x} 1}=$ gaya geser ultimit

- Perhitungan frekuensi natural

$$
f_{n x}=\frac{1}{2 \pi} \times \sqrt{\frac{k_{x}}{m}}
$$

Dimana :

$\mathrm{K}_{\mathrm{x}}=$ konstanta kekakuan $(\mathrm{t} / \mathrm{m})$

$\mathrm{m}=$ massa struktur pondasi $\left(\mathrm{t} . \mathrm{m} / \mathrm{det}^{2}\right)$

- Perhitungan amplitudo horizontal

$$
A_{x d}=\frac{P_{x}}{k_{x} \sqrt{\left(1-\left(\frac{\omega}{\omega_{n x}}\right)^{2}\right)^{2}+\left(2 D_{x}\left(\frac{\omega}{\omega_{n x}}\right)\right)^{2}}}
$$

Dimana :

$\mathrm{P}_{\mathrm{x}}=$ beban dinamis $\left(\mathrm{t} \cdot \mathrm{rad}^{2}\right)$

$\mathrm{D}_{\mathrm{x}}=$ redaman

$\mathrm{K}_{\mathrm{x}}=$ konstanta kekakuan $(\mathrm{t} / \mathrm{m})$

ù = kecepatan operasi $(\mathrm{rad} / \mathrm{sec})$

$\grave{\mathrm{u}}_{\mathrm{nx}}=$ kecepatan natural $(\mathrm{rad} / \mathrm{sec})$

- Analisa getaran goyangan

- Perhitungan konstanta kekakuan

$$
K_{y}=G r o^{3}\left(C_{y 1}+\frac{G}{G} \frac{h}{r o}\left(S_{y 1}+\frac{h^{2}}{3 r o^{2}} S_{x 1}\right)\right)
$$

Dimana :

$\mathrm{G}=$ modulus geser tanah $\left(\mathrm{t} / \mathrm{m}^{2}\right)$

ro $=$ radius ekivalen $(\mathrm{m})$

$\mathrm{h}=$ kedalaman tertanam $(\mathrm{m})$

$\mathrm{C}_{\mathrm{y} 1}=$ kohesifitas tanah

$\mathrm{S}_{\mathrm{y} 1}=$ gaya geser ultimit

- Perhitungan frekuensi natural

$$
f_{n y}=\frac{1}{2 \pi} \times \sqrt{\frac{k_{y}}{m}}
$$

Dimana :

$\mathrm{K}_{\mathrm{y}}=$ konstanta kekakuan $(\mathrm{t} / \mathrm{m})$

$\mathrm{m}=$ massa struktur pondasi (t.m/det $\left.{ }^{2}\right)$
- Perhitungan amplitudo goyangan

$$
A_{y}=\frac{M_{y}}{k_{y} \sqrt{\left(1-\left(\frac{\omega}{\omega_{n y}}\right)^{2}\right)^{2}+\left(2 D_{y} \frac{\omega}{\omega_{n y}}\right)^{2}}}
$$

Dimana :

$M_{y}=$ momen inersia pada sumbu y $\left(t \cdot m \cdot d^{2}{ }^{2}\right)$

$\mathrm{D}_{\mathrm{y}}=$ redaman

$\mathrm{K}_{\mathrm{y}}=$ konstanta kekakuan $(\mathrm{t} / \mathrm{m})$

ù = kecepatan operasi $(\mathrm{rad} / \mathrm{sec})$

$\grave{\mathrm{u}}_{\mathrm{ny}}=$ kecepatan natural $(\mathrm{rad} / \mathrm{sec})$

- Analisa getaran kombinasi

$$
\begin{aligned}
& k_{\phi 1}=G r o^{3}\left\{\begin{array}{l}
C_{\phi 1}+\left(\frac{L}{r o}\right)^{2} C_{x 1}+\frac{G_{s}}{G}\left(\frac{h}{r o}\right) S_{\phi 1}+ \\
\left(\frac{G_{s}}{G}\right)\left(\frac{h}{r o}\right) x\left(\frac{h^{2}}{3 r o^{2}}+\frac{L^{2}}{r o^{2}}-\frac{h \cdot L}{r o^{2}}\right) S_{x 1}
\end{array}\right\} \\
& k_{\phi 2}=-G r o\left\{L C_{x 1}+\left(\frac{G_{s}}{G}\right)\left(\frac{h}{r o}\right)\left(L-\frac{h}{2}\right) S_{x 1}\right\}
\end{aligned}
$$

Dimana :

$\mathrm{G}=$ modulus geser $\operatorname{tanah}\left(\mathrm{t} / \mathrm{m}^{2}\right)$

$\mathrm{L}=$ panjang pondasi $(\mathrm{m})$

ro $=$ radius ekivalen $(\mathrm{m})$

$\mathrm{h}=$ kedalaman tertanam $(\mathrm{m})$

$\mathrm{C}=$ kohesifitas tanah

S = gaya geser ultimit, (Sidartha, 1996:18)

- Perhitungan frekuensi natural

$$
f_{\phi 1.2}^{2}=\frac{1}{2}\left(\frac{k x}{m}+\frac{k \phi}{M m}\right) \pm \sqrt{\frac{1}{4}\left(\frac{k x}{m}-\frac{k \phi}{M m}\right)^{2}+\frac{k x \phi^{2}}{m \cdot M m}}
$$

Dimana :

$\mathrm{K}=$ konstanta kekakuan $(\mathrm{t} / \mathrm{m})$

$\mathrm{m}=$ massa struktur pondasi $\left(\mathrm{t} . \mathrm{m} / \mathrm{det}^{2}\right)$

$\mathrm{Mm}=$ momen inersia massa (t.m. $\left.\operatorname{det}^{2}\right)$

- Perhitungan amplitudo vertikal

$$
\begin{aligned}
& A_{v}=\frac{a}{2} x A_{\phi 1} \\
& A_{h}=A_{x}+h \cdot A_{\phi 2}
\end{aligned}
$$


Dimana :

$A_{v}=$ total amplitudo vertical

a = panjang pondasi

$\mathrm{A}_{\ddot{O} 1}=$ amplitudo goyangan

$\mathrm{Ah}=$ total amplitudo horizontal

Ax $=$ amplitudo horizontal

$\mathrm{h}=$ jarak antara pusat rotor terhadap pusat gravitasi

$\mathrm{A}_{\ddot{\mathrm{O}} 2}=$ amplitudo goyangan

- Perhitungan Daya Dukung Tanah

Pondasi yang bersandar pada tanah lempung berpasir $\left(\varnothing=7^{0}\right.$ dan $\left.\mathrm{C}=\mathrm{C}_{\mathrm{u}}\right)$ memiliki persamaan sebagai berikut. (Das, Braja M, $1984: 230$ )

$q_{u}=c \cdot \lambda_{c s} \cdot \lambda_{c d} \cdot N_{c}+q \cdot \lambda_{q s} \cdot \lambda_{q d} N_{q}+\frac{1}{2} \lambda_{\gamma s} \cdot \lambda_{\gamma d} \cdot \gamma B N_{\gamma}$

Dimana :

$\lambda_{c s}, \lambda_{q s}, \lambda_{v s}=$ faktor bentuk untuk untuk bentuk persegi

$\lambda_{c d}, \lambda_{q d}, \lambda_{r d}=$ faktor kedalaman

$\mathrm{N}_{\mathrm{c}} \quad=$ faktor kapasitas daya dukung

$\mathrm{N}_{\mathrm{q}} \quad=$ faktor kapasitas daya dukung

$\mathrm{N}_{\tilde{\mathrm{a}}}^{\mathrm{q}} \quad=$ faktor kapasitas daya dukung

$\mathrm{B}=$ lebar pondasi $(\mathrm{m})$

\section{Specifikasi Generator dan Turbin}

Generator

Berat (Wg)

Berat Rotor (Wr)

Kec. Operasi (f) rpm

Panjang Generator

$=115,77 \mathrm{rad} / \mathrm{sec}$

Lebar Generator

$=4,1 \mathrm{~m}$

$=2,5 \mathrm{~m}$

- Turbin

Berat (Wt)

Berat Rotor $(\mathrm{Wr})$

$=14200 \mathrm{~kg}$

Kec. Operasi (f)

$=500 \mathrm{~kg}$

$=8900 \mathrm{rpm}=$

$148,33 \mathrm{rad} / \mathrm{sec}$

Panjang Turbin

$=4,1 \mathrm{~m}$

Lebar Turbin

$=4,4 \mathrm{~m}$

Tinggi turbin

\section{Data Tanah}

Kondisi tanah dibawah struktur adalah tanah lempung dan berada pada zona 4 dari peta wilayah gempa untuk Indonesia (PPTGIUG' 83).

Dari pengamatan tanah diperoleh data-data sebagai berikut : (Data tanah diperoleh dari Pabrik Gula Cukir Jombang).

- Berat volume tanah (ã) $=1,692 \mathrm{t} / \mathrm{m}^{3}$

- Modulus geser tanah $(\mathrm{G})=2145,8077 \mathrm{t} / \mathrm{m}^{2}$

- Sudut geser dalam $(\varnothing)=7^{0}$

- Angka poison (i) $\quad=0,4$

- Angka pori (e) $\quad=1,422$

\section{Lingkup Pembahasan}

- Perhitungan beban dinamis

- Perhitungan dimensi rencana pondasi dinamis

- $\quad$ Perhitungan model struktur yang bekerja pada pondasi pendukung mesin turbin

- Perhitungan daya dukung tanah

- Perhitungan penurunan tanah (Diplacement)

METODE PENELITIAN

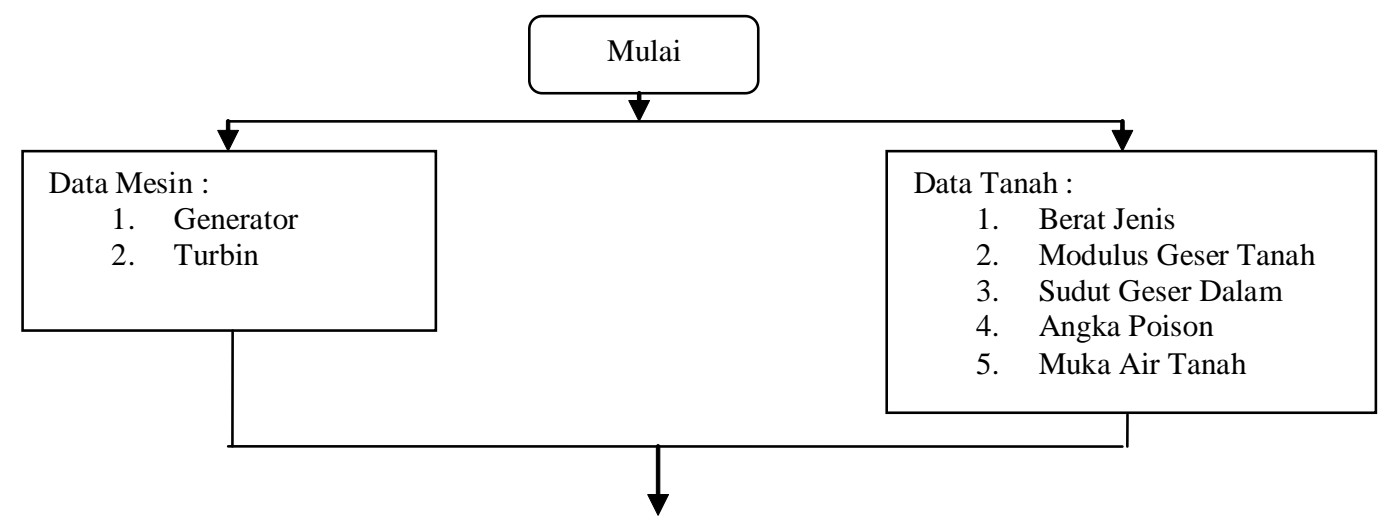




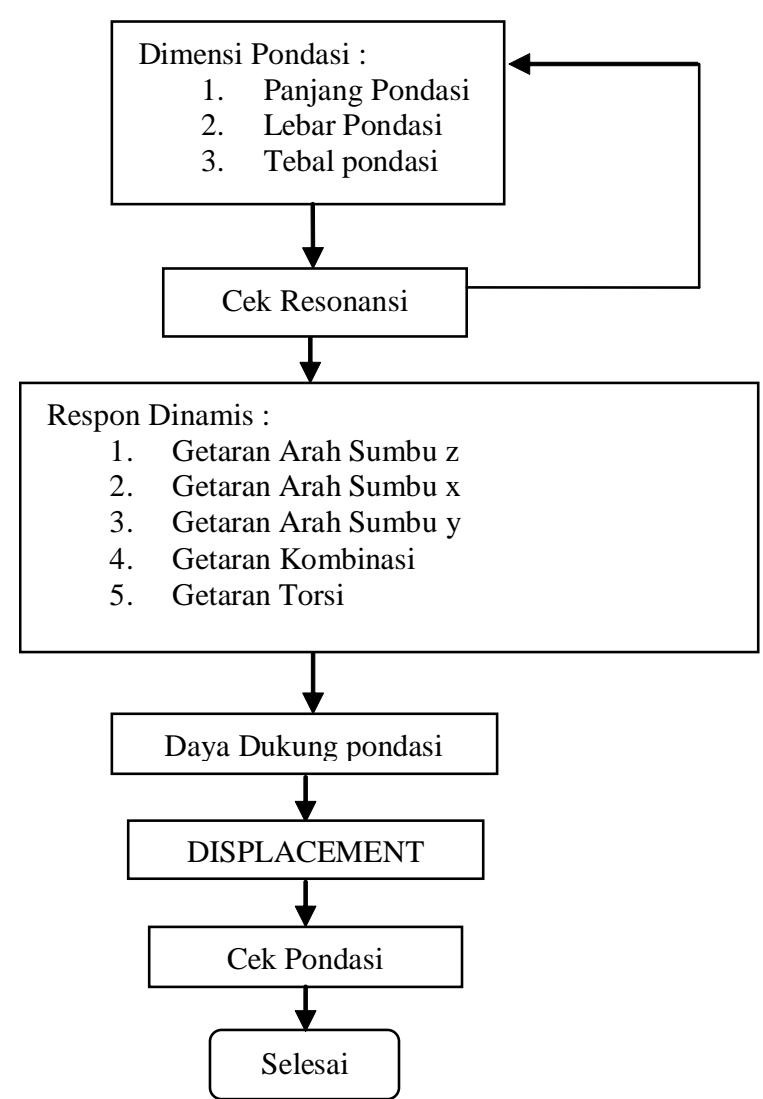

Gambar 1. Diagram alir perencanaan

\section{HASIL DAN PEMBAHASAN}

Pembebanan

- Eksentrisitas arah $\mathrm{x}$ dan $\mathrm{y}$

Dari arah y

$$
\begin{aligned}
& \mathrm{PR}_{\text {Generator }}=1,265 \mathrm{~m} \text { dari elevasi 00,00 } \\
& \mathrm{PR}_{\text {Turbin }}=0.630+0,085=0,715 \mathrm{~m} \text { dari } \\
& \text { elevasi } 00,00 \\
& \mathrm{PM}_{\text {Pondasi }} \quad=2,8 \times 1 / 2 \quad=1,4 \mathrm{~m}
\end{aligned}
$$

Dari $\operatorname{arah} \mathrm{x}$

$\mathrm{PR}_{\text {Generator }}$ $=2,850+0,235+0,35=3,435 \mathrm{~m}$ dari tepi pondasi

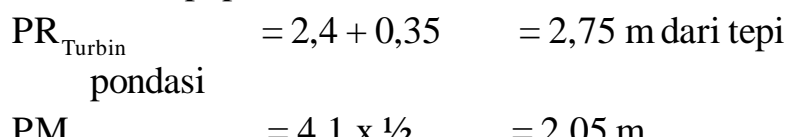

$$
\mathrm{PM}_{\text {Pondas }} \quad \mathrm{i}=4,1 \times 1 / 2 \quad=2,05 \mathrm{~m}
$$

\section{Generator}

$$
\begin{aligned}
& \mathrm{e}_{\mathrm{y}}=\mathrm{PR}_{\text {Generator }}+\mathrm{PM}_{\text {Pondasi }}=1,265+1,4= \\
& \text { 2,665 m } \\
& \mathrm{e}_{\mathrm{x}}=\mathrm{PR}_{\text {Generator }}-\mathrm{PM}_{\text {Pondasi }}=3,435-2,05= \\
& 1,385 \mathrm{~m}
\end{aligned}
$$

\section{Turbin}

$\mathrm{e}_{\mathrm{y}} \quad \mathrm{PR}_{\text {Turbin }}+\mathrm{PM}_{\text {Pondasi }}=0,715+1,4$
$2,115 \mathrm{~m}$

$$
\begin{array}{ll}
\mathrm{e}_{\mathrm{x}} & =\mathrm{PR}_{\text {Turbin }}-\mathrm{PM}_{\text {Pondasi }}=2,75-2,05= \\
& 0,7 \mathrm{~m}
\end{array}
$$$$
\mathrm{P}_{\text {Generator }}=\mathrm{m} \text {. e. } \mathrm{f}^{2}
$$$$
=\left(\frac{16,3}{9,81}\right) \times 2,665 \times 115,77^{2}
$$$$
=59348,24 \text { t.rad }{ }^{2}
$$

$\mathrm{P}_{\text {Turbin }}=\mathrm{m}$. e. $\mathrm{f}^{2}$

$$
\begin{aligned}
& =\left(\frac{14,2}{9,81}\right) \times 2,115 \times 148,33^{2} \\
& =67357,77{\mathrm{t} \cdot \mathrm{rad}^{2}}^{2} \\
\mathrm{P}_{\text {Total }} & =\mathrm{P}_{\text {Generator }}+\mathrm{P}_{\text {Turbin }} \\
& =59348,24+67357,77=126706,01{\mathrm{t} \cdot \mathrm{rad}^{2}}^{2}
\end{aligned}
$$

\section{Sifat Geometrik Pondasi}

Berat Komponen

Berat Turbin $\quad=14,2$ ton

Berat Generator $\quad=16,3$ ton

Beban Pondasi $=186,906$ ton

$=$ Total Pembebanan $(\mathrm{P})$ 
(P) $\quad=\mathrm{P} 1+\mathrm{P} 2+\mathrm{P} 3$

$=14,2+16,3+186,906=217,406$ ton

\section{Massa komponen}

Massa Turbin

$$
\text { (m) } \begin{aligned}
& =\mathrm{W} / \mathrm{g} \\
& =14,2 / 9,81=1,448 \mathrm{t} / \mathrm{m}^{-1} \mathrm{det}^{-2}
\end{aligned}
$$

Massa Generator

$$
\text { (m) } \begin{aligned}
& =\mathrm{W} / \mathrm{g} \\
& =16,3 / 9,81=1,662 \mathrm{t} / \mathrm{m}^{-1} \mathrm{det}^{-2}
\end{aligned}
$$

Massa pondasi

$$
\begin{aligned}
\operatorname{Bagian} \mathrm{I}(\mathrm{W}) & =141,748 \text { ton } \\
(\mathrm{m}) & =\mathrm{W} / \mathrm{g} \\
& =141,748 / 9,81=14,449 \mathrm{t} / \mathrm{m}^{-1} \operatorname{det}^{-2} \\
\text { Bagian II(W) } & =45,158 \text { ton } \\
(\mathrm{m}) & =\mathrm{W} / \mathrm{g} \\
& =45,158 / 9,81=4,603 \mathrm{t} / \mathrm{m}^{-1} \operatorname{det}^{-2}
\end{aligned}
$$

\section{Perhitungan Akhir Pondasi}

Analisa Getaran Vertikal

Perhitungan Radius Ekivalen

$$
\begin{aligned}
& k z=G r o\left(C i+\frac{G s \cdot h}{G \cdot r o} S i\right) \\
& \left.=214,80 \times 3,7506,58+\left(\frac{0,75 \times 214,80}{214,80} \times \frac{0,6}{3,750}\right) \times 2,70\right) \\
& =145566,23 \mathrm{t} / \mathrm{m}
\end{aligned}
$$

Perhitungan konstanta redaman vertikal (Dz)

$$
\begin{aligned}
\text { bo } & =\frac{\omega}{\gamma r o^{3}}=\frac{(B x L x H) x B j_{\text {Beton }}}{\gamma r o^{3}} \\
& =\frac{186,906}{1,692 \times 3,750^{3}} \\
& =2,095 \mathrm{~m} \\
\rho & =\frac{\gamma}{\text { gravitasi }} \\
& =\frac{1,692}{9,81} \\
& =0,172 \mathrm{t} / \mathrm{m}^{3} \\
D z & =\frac{1}{2 \sqrt{b o}} x \frac{\left(C_{2}+S_{2} \frac{h}{r o} \sqrt{\left(\frac{\rho_{s}}{\rho}\right) x\left(\frac{G_{s}}{G}\right)}\right)}{\sqrt{C i+\left(\frac{G_{s}}{G}\right) x\left(\frac{h}{r o}\right) S i}}
\end{aligned}
$$

$\mathrm{Dz}=\frac{1}{2,095}\left(\frac{6,08+6,70 \times \frac{0,6}{3,750} \sqrt{\frac{0,172}{0,172} \times \frac{1609,356}{2145,8077}}}{\sqrt{6,08+\left(\frac{1609,356}{2145,8077} \times \frac{0,6}{3,750}\right) \times 2,70}}\right)$

$$
=1,322 \mathrm{~mm}
$$

Perhitungan frekuensi natural

$$
\begin{aligned}
f_{n z} & =\frac{1}{2 \pi} \times \sqrt{\frac{k_{z}}{m}} \\
& =\frac{1}{2 \pi} \times \sqrt{\frac{145566,23}{22,162}}=12,9 \mathrm{rad} / \mathrm{sec}
\end{aligned}
$$

Kontrol frekuensi resonansi

$$
r o=\sqrt{\frac{A}{\pi}}
$$

$=\sqrt{\frac{4,8 \times 9,2}{3,14}}$

$$
=3,750 \mathrm{~m}
$$

Perhitungan konstanta kekakuan vertikal (kz)

$\mathrm{f}_{\mathrm{nz}}<\mathrm{f}_{\mathrm{op}}$

$$
12,9 \mathrm{rad} / \mathrm{sec}<115,77 \mathrm{rad} / \mathrm{sec}
$$

Perhitungan amplitudo vertikal

$$
A_{z d}=\frac{P_{z}}{k_{z} \sqrt{\left(1-\left(\frac{\omega}{\omega_{n z}}\right)^{2}\right)^{2}+\left(2 D_{z}\left(\frac{\omega}{\omega_{n z}}\right)\right)^{2}}}
$$

$=\frac{126706,01}{145566,23 \sqrt{\left(1-\left(\frac{115,77}{53,196}\right)^{2}\right)^{2}+\left(2 \times 1,322\left(\frac{115,77}{53,196}\right)\right)^{2}}}$

$=0,000127 \mathrm{~m}=0,127 \mathrm{~mm}$

Perhitungan pada kondisi horizontal, goyangan, kombinasi vertikal, kombinasi horizontal dan torsional ditabelkan pada tabel 1 terlampir :

\section{Perhitungan daya dukung pondasi}

$$
\begin{aligned}
& q_{u}=c \cdot \lambda_{c s} \cdot \lambda_{c d} \cdot N_{c}+q \cdot \lambda_{q s} \cdot \lambda_{q d} N_{q}+\frac{1}{2} \lambda_{\gamma s} \cdot \lambda_{\gamma d} \cdot \gamma B N_{\gamma} \\
& =1,5 \times 1,14 \times 1,58 \times N_{c}+5,076 \times 1,06 \times 1,10 \times N_{q} \\
& +0,5 \times 0,79 \times 1 \times 1,692 \times 4,8 \times N_{\gamma}
\end{aligned}
$$




$$
=2,7 \mathrm{~N}_{\mathrm{c}}+5,9 \mathrm{~N}_{\mathrm{q}}+3,2 \mathrm{~N}_{\tilde{\mathrm{a}}}
$$

Faktor bentuk untuk pondasi bentuk persegi :

$$
\lambda_{\gamma s}=1-0,4\left(\frac{4,8}{9,2}\right)=0,79
$$

$$
\begin{aligned}
& \lambda_{c s}=1+\left(\frac{B}{L}\right)\left(\frac{N_{q}}{N_{c}}\right) \\
& \lambda_{c s}=1+\left(\frac{4,8}{9,2}\right)\left(\frac{1,88}{7,16}\right)=1,14 \\
& \lambda_{q s}=1+\left(\frac{B}{L}\right)(\tan \phi) \\
& \lambda_{q s}=1+\left(\frac{4,8}{9,2}\right)\left(\tan 7^{\circ}\right)=1,06 \\
& \lambda_{\gamma s}=1-0,4\left(\frac{B}{L}\right)
\end{aligned}
$$

Faktor kedalaman :

$$
\begin{aligned}
\lambda_{q d} & =1+2 \tan \phi(1-\sin \phi)^{2}\left(\frac{D_{f}}{B}\right) \\
\lambda_{q d} & =1+2 \tan 7^{\circ}\left(1-\sin 7^{\circ}\right)^{2}\left(\frac{2,8}{4,8}\right) \\
& =1,10 \\
\lambda_{c d} & =\lambda_{q d}-\frac{1-\lambda_{q d}}{N_{q} \cdot \tan \phi} \\
\lambda_{c d} & =1,10-\frac{1-1,10}{1,88 \cdot \tan 7^{\circ}} \\
& =1,58
\end{aligned}
$$

Tabel 1 Kapasitas daya dukung untuk mesin turbin dan generator

\begin{tabular}{cccccccccc}
\hline No & $\begin{array}{c}\mathrm{H} \\
(\mathrm{m})\end{array}$ & $\begin{array}{c}\mathrm{K} \\
(\mathrm{t} / \mathrm{m})\end{array}$ & $\mathrm{N} \gamma$ & $\mathrm{Nc}$ & $\mathrm{Nq}$ & $\mathrm{Ni}$ & $\sqrt{\frac{N R}{N i}}$ & $\begin{array}{c}\mathrm{Qu} \\
\left(\mathrm{t} / \mathrm{m}^{2}\right)\end{array}$ & $\begin{array}{c}\text { Qun } \\
\left(\mathrm{t} / \mathrm{m}^{2}\right)\end{array}$ \\
& & & & & & & & \\
\hline 1 & 1 & 0,10 & 0,45 & 6,49 & 1,57 & 2,93 & 5,88 & 28,226 & 9,408667 \\
2 & 1 & 0,05 & 0,57 & 6,81 & 1,72 & 2,92 & 5,74 & 30,359 & 10,11967 \\
3 & 0,8 & 0,0 & 0,71 & 7,16 & 1,88 & 2,91 & 5,61 & 32,696 & 10,89867 \\
\hline
\end{tabular}

Sumber : Hasil perhitungan

$$
\begin{aligned}
q_{i z i n} & =\frac{q_{u}}{F s} \\
& =\frac{28,226}{3} \\
& =9,41 \mathrm{t} / \mathrm{m}^{2}
\end{aligned}
$$

$\mathrm{DL}=\left(\mathrm{H}_{\text {pondasi }} \times \mathrm{Bj}\right)+($ Berat mesin/ luasan $)$

$$
=2,8 \times 2,4+\frac{30,5}{4,8 \times 9,2}
$$

$$
\begin{aligned}
& =4,641 \mathrm{t} / \mathrm{m}^{2} \\
\mathrm{Q} & =1+4,641 \\
& =5,641 \mathrm{t} / \mathrm{m}^{2}
\end{aligned}
$$$$
\mathrm{A}_{\text {max }}=\frac{0,002}{0,1999}=0,010 \mathrm{~m}=10 \mathrm{~mm}
$$

Tegangan tanah yang terjadi di bawah pondasi bisa dihitung dengan rumus sebagai berikut :
- Tekanan tanah arah sumbu z

$$
\sigma_{z}=\frac{F_{t z}}{A}=\frac{12,9}{44,16}=0,292 \mathrm{t} / \mathrm{m}^{2}
$$

- Tekanan tanah arah sumbu x

$$
\sigma_{z}=\frac{F_{t x}}{A}=\frac{7,5}{44,16}=0,170 t / \mathrm{m}^{2}
$$

- Tekanan tanah arah sumbu y

$$
\sigma_{z}=\frac{F_{t y}}{A}=\frac{11,91}{44,16}=0,270 t / \mathrm{m}^{2}
$$

- Tekanan tanah kombinasi arah vertikal dan horizontal

$$
\sigma_{\phi 1}=\frac{M_{x}}{W_{x}}=\frac{26,969}{1 / 6 \times 4,8 \times(9,2)^{2}}=0,398 t / m^{2}
$$

$$
\sigma_{\phi 2}=\frac{M_{y}}{W_{y}}=\frac{158,265}{1 / 6 \times 9,2 \times(4,8)^{2}}=4,476 t / m^{2}
$$


- Tekanan tanah akibat gaya torsi

$\sigma_{\psi}=\frac{F_{\psi}}{A}=\frac{6,51}{4,8 \times 9,2}=0,147 \mathrm{t} / \mathrm{m}^{2}$

\section{Perhitungan penulangan pondasi}

Dari hasil analisa di peroleh :

$\begin{array}{ll}\text { Panjang (B) } & =9,8 \mathrm{~m} \\ \text { Lebar (L) } & =4,2 \mathrm{~m} \\ \text { Kedalaman (H) } & =2,8 \mathrm{~m} \\ \text { Mutu Baja (fy) } & =400 \mathrm{Mpa} \\ \text { Mutu Beton (fc) } & =30 \mathrm{Mpa} \\ \text { Berat Jenis (ãb) } & =2400 \mathrm{~kg} / \mathrm{m}^{3}\end{array}$

Perencanaan penulangan:

- Penulangan pada potongan A - A (sisi lebar) As perlu $=\tilde{\mathrm{n}} \cdot \mathrm{b} \cdot \mathrm{h}=0,0018 \times 4800 \times 2800=$ $24192 \mathrm{~mm}^{2}$

Dipakai tulangan 24D36 ( As $=24429,6 \mathrm{~mm}^{2}$ )

- Penulangan pada potongan B - B ( sisi panjang)

As perlu $=\tilde{\mathrm{n}} \cdot \mathrm{b} \cdot \mathrm{h}=0,0018 \times 9200 \times 2800=$ $46368 \mathrm{~mm}^{2}$

Dipakai tulangan 38D40 ( As $\left.=47826 \mathrm{~mm}^{2}\right)$

\section{KESIMPULAN DAN SARAN}

\section{Kesimpulan}

Amplitudo yang dihasilkan sebagai berikut: amplitudo arah z 0,127 mm, amplitudo arah x 0,142 $\mathrm{mm}$, amplitudo arah y $0,19 \mathrm{~mm}$, amplitudo kombinasi vertikal 0,0083 rad, amplitudo kombinasi horizontal $0,0027 \mathrm{rad}$ dan amplitudo torsi 0,00159 rad.

Dimensi yang mampu menahan beban dinamis mesin yaitu dengan panjang 9,2 $\mathrm{m}$, lebar 4,8 $\mathrm{m}$ dan kedalaman $2,8 \mathrm{~m}$.

\section{Saran}

Perencanaan pondasi dinamis ini dapat dicoba memakai bentuk-bentuk pondasi yang lain seperti tipe box, tipe wall, dan tipe frame yang disesuaikan dengan kebutuhan dan tipe mesin.

Perencanaan pondasi dinamis ini dapat juga dianalisis dengan memakai metode yang berbeda, dengan memasukkan respon dinamis perilaku pondasi dalam perencanaannya.

\section{DAFTAR PUSTAKA}

Bowles, J.E. 1993. Analisis dan Desain Pondasi. Terjemahan Ir. Johan Kelanaputra Hainim. Erlangga, Jakarta

Das, Braja M. 1984. Pondasi Tanah Dinamis. Erlangga, Jakarta

Prakash, S and Puri Vijay K. 1988. Foundation for Machine : Analysis and Design. John Willey and Sons, New York

Richart, FE. Jr and Woods, RD. 1970. Vibrations of Soils and Foundations. Englewood Cliffs, New Jersey

Sidartha, S.A. 1996. Analisis Pondasi Dinamis untuk Mendukung Mesin Generator Pembangkit Listrik Tenaga Uap. ITS, Surabaya

Srinivasulu, P and Vaidyanathan, CV. 1976. Handbook of Machines Foundation. MC Graw Hill, New Delhi 